\title{
SEGURANÇA MÁXIMA, REPRESÁLIA MÁXIMA: A TRANSFERÊNCIA DE PRESOS DA CÚPULA DO PCC
}

\section{LUCAS MARTINS MIRANDA CHELALA}

Graduando em Direito, modalidade Integral. Escola Superior Dom Helder Câmara ESDHC - Belo Horizonte - MG. E-mail: mathchelala@gmail.com

\section{CAIO AUGUSTO SOUZA LARA}

Mestre e Doutor em Direito pela Faculdade de Direito da Universidade Federal de Minas Gerais - UFMG. Professor da Escola Superior Dom Helder Câmara. Pesquisador Associado ao Programa RECAJ-UFMG - Acesso à Justiça e Solução de Conflitos. Secretário de Comunicação do Conselho Nacional de Pesquisa e Pósgraduação em Direito - CONPEDI. Belo Horizonte-MG. E-mail: caiolarabh@yahoo.com.br

\section{RESUMO}

A pesquisa que ora se apresenta consiste na avaliação, sob perspectiva sociológica, das últimas transferências de presos na cúpula do Primeiro Comando Capital. Estas ações resultaram em diversas consequências para a sociedade brasileira. O problema objeto da investigação científica proposta é: as transferências realizadas deram bons frutos e devem ser continuamente aplicadas em casos futuros? Com o escrutínio das reflexões preliminares sobre o tema, é possível afirmar aprioristicamente que as transferências foram "medidas de pronto-socorro" que provam a necessidade de repensar o modelo de segurança pública e de Justiça que 
DOI:

\section{Personalidade Acadêmica Homenageada:}

Raymundo Juliano Feitosa (Universidade Federal do Rio Grande do Norte - UFRN)

vem sendo implementado nas últimas décadas. Como objetivo geral, analisa-se o caráter equivocado de tratamento do Estado na realização de transferências, refletindo um falacioso pretexto em que seus resultados perduram por pouco tempo. A pesquisa que se propõe pertence à vertente metodológica jurídico-sociológica. No tocante ao tipo de investigação, foi escolhido, na classificação de Witker (1985) e Gustin (2010), o tipo jurídico-projetivo. O raciocínio desenvolvido na pesquisa será predominantemente dedutivo. De acordo com a técnica de análise de conteúdo, afirma-se que trata-se de uma pesquisa teórica, o que será possível a partir da análise de conteúdo dos textos doutrinários, normas e demais dados colhidos na pesquisa. De maneira recôndita ao senso comum, tudo esposado na execução da deslocação entre presídios faz facções crescerem. Seu líder, Marcola, já foi transferido para um RDD (Regime Disciplinar Diferenciado) mas mesmo assim as engrenagens da prémafia continuam rodando, explicitando como o gingado de prisão em prisão é inefetivo. Vivenciamos no Brasil o sucateamento das estruturas administrativas e do próprio estado, e em todos os Estados da federação, a segurança pública sofre pelos males da corrupção institucionalizada dos agentes e do crime organizado que tem suas próprias leis de comando, como dito por Oliveira (2018). O governo utiliza de uma faca de dois gumes - visando frear o império do crime em um estado específico, as transferências permitem que a cúpula cresça em âmbito federal. O crime organizado cresce paulatinamente no Brasil, e essa realidade no que tange o PCC é indubitável: o poderio do crime organizado está intrinsecamente ligado ao sistema prisional brasileiro. Não importa a segregação, enquanto os presos tiverem códigos inextricáveis ao "bom convívio" dentro das penitenciárias, mais adeptos nascerão, e o crime organizado seguirá vivo. Para ser considerado um homem de proceder em cadeias do Comando, não basta seguir o Estatuto do PCC, mas faz-se necessário atender a uma vasta lista de orientações, que interfere nos mais sutis gestos, palavras e condutas, que permeiam toda a existência do preso na instituição penal (BIONDI, 2009). O PCC deixou de ser uma facção por muito - se aproxima mais de uma 
DOI:

Personalidade Acadêmica Homenageada:

Raymundo Juliano Feitosa (Universidade Federal do Rio Grande do Norte - UFRN)

metodologia de vida, uma ideia, do que uma estrutura organizada. E é com essas características fluidas que sua ética se espalha de estado em estado sem a necessidade de ordens superiores. Dito isso, desde 2011, o Primeiro Comando Capital vem criando uma "sintonia de rua", afinal, medidas para prevenir a comunicação dos que estão no topo da hierarquia com os membros menores são aplicadas pelo Estado. Então foi criada uma estrutura que desse mais autonomia aos que estão na rua, sem a necessidade de um aval superior. Isso, adicionado com o conceito de que a facção já se tornou uma ideia, revela mais uma vez a ineficácia da metodologia hodierna no tratamento dos líderes. Buscou-se, então, evidenciar outras medidas de premência capazes de lidar com a problemática, complementadas com soluções de médio e longo prazo, com o objetivo de demonstrar as condições de desenvolvimento de processos alternativos.

PALAVRAS-CHAVE: Transferência de presos; Primeiro Comando Capital; Direito Processual Penal.

\section{REFERÊNCIAS}

AMORIM, Carlos. CV_PCC: A Irmandade do Crime. Rio de Janeiro: Record, 2010.

BIONDI, Karina. Junto e Misturado: Imanência e Transcendência no PCC. 2009. 198 f. Dissertação (Mestrado em Antropologia Social) - Universidade Federal de São Carlos, São Carlos, 2009.

FAGUNDEZ, Ingrid. PCC não precisa de líderes para acontecer, diz autora de livro sobre a facção. Portal BBC News Brasil. 8 jan. 2017. Disponível em https://www.bbc.com/portuguese/brasil-38538309. Acesso em 09 maio 2019.

FELTRAN, Gabriel. Irmãos - Uma história do PCC. São Paulo: Companhia das Letras, 2018. 
DOI:

Personalidade Acadêmica Homenageada:

Raymundo Juliano Feitosa (Universidade Federal do Rio Grande do Norte - UFRN)

FELLET, João. PCC financia igrejas e pode influenciar eleição, diz ex-desembargador. Portal BBC News Brasil. 11 jan 2018. Disponível em https://www.bbc.com/portuguese/brasil-42643310. Acesso em 09 maio 2019.

GRECO, Rogério. Sistema Prisional: Colapso Atual e Soluções Alternativas. Niterói: Impetus, 2015.

GUSTIN, Miracy Barbosa de Sousa; DIAS, Maria Tereza Fonseca. (Re)pensando a pesquisa jurídica: teoria e prática. 3a․ ed. Belo Horizonte: Del Rey, 2010.

LOPES, Nathan. SP atrasou mudança de Marcola por medo de retaliação do PCC, critica juiz. Portal UOL. 14 fev. 2019. Disponível em https://noticias.uol.com.br/cotidiano/ultimas-noticias/2019/02/14/retaliacao-marcolatransferencia-lideres-pcc-juiz.htm. Acesso em 07 maio 2019.

MADER, Helena; STACCIARINI, Isa; SOUZA, Renato. Transferência de presos do PCC aumenta preocupação com a segurança. Correio Braziliense. 14 fev. 2019. Disponível em https://www.correiobraziliense.com.br/app/noticia/cidades/2019/02/14/interna_cidade sdf,737390/transferencia-de-presos-do-pcc-aumenta-preocupacao-com-aseguranca.shtml. Acesso em 07 maio 2019.

OLIVEIRA, José Sebastião de. Violações aos direitos da personalidade com o decreto de intervenção federal no rio de janeiro: aspectos que devem nortear o Estado Democrático de Direito em conflito com direito fundamentais em face da possibilidade de realização de busca e apreensão "genérica" via mandado coletivo, concedida pelo poder judiciário. Revista Jurídica - UNICURITIBA. Curitiba, vol. 02, n. 51, p. 166, abr. 2018.

PERON, Isadora. Transferência de Marcola mostra estratégia contra crime organizado. Econômico Valor. 14 fev 2019. Disponível em https://www.valor.com.br/politica/6118895/transferencia-de-marcola-mostraestrategia-contra-crime-organizado. Acesso em 04 maio 2019.

SALLA, Fernando. Decifrando as dinâmicas do crime. Revista Brasileira de Ciências Sociais, São Paulo, v. 29, n. 87, p. 176, out. 2014

VIEIRA, André. Coautor de livro do PCC fala sobre transferência de líderes presos: 'medida de pronto-socorro' Metro Jornal. 18 fev. 2019. Disponível em https://www.metrojornal.com.br/foco/2019/02/18/pcc-transferencia-lideres-presosentrevista.html. Acesso em 04 maio 2019. 
Percurso - ANAIS do IV CONLUBRADEC

(Congresso Luso-Brasileiro de Direito Empresarial e Cidadania)

vol.04, n०.31, Curitiba, 2019. pp. $265-269$

DOI:

Personalidade Acadêmica Homenageada:

Raymundo Juliano Feitosa (Universidade Federal do Rio Grande do Norte - UFRN)

VILARDAGA, Vicente; LAVIERI, Fernando. A facção que mais cresce no mundo. Istoé. 03 ago 2018. Disponível em https://istoe.com.br/a-faccao-que-mais-cresce-nomundo. Acesso em 04 maio 2019.

WITKER, Jorge. Como elaborar una tesis en derecho: pautas metodológicas y técnicas para el estudiante o investigador del derecho. Madrid: Civitas, 1985. 